\title{
O Mercosul e o Direito Comunitário
}

\author{
Luiz Roberto Sabbato
}

SUMÁRIO: 1. Introdução. 2. O Direito Comunitário: Definiçóes e Fontes. 3. O Direito Originário. 4. O Direito Derivado. 5. O Direito Complementar. 6.O Direito Jurisprudencial. 7. Conclusão. 8. Bibliografia.

SUMMARY: 1. Introduction. 2. The European Community law: Definitions and Sources. 3.The Originary Right. 4. The Derived Right. 5. The Complementary Right. 6. The Jurisprudencial Right. 7. Conclusion. 8. Bibliography.

SUMARIO: 1. Introducción. 2. La ley de la Comunidad Europea: Definiciones y fuentes. 3.Lo Derecho Originario. 4. Lo Derecho Derivado. 5. Lo Derecho Complementar. 6. Lo Derecho Jurisprudencial. 7. Conclusión. 8. Bibliografia.

RESUMO: Ante a tendência, em todo o planeta, da formação de blocos regionais macrocconômicos, o conhecimento do Direito Comunitário, novo ramo do Direito, vem-se tornando necessidade não só entre os responsáveis pelo destino do projeto, como também entre os que já compreenderam que a globalização, mais do que irreversível, é "irresistível". Faz algumas considerações sobre o Direito Comunitário, fornecendo noções introdutórias, conceituação, definição, princípios e fontes. Destaca as modalidades das fontes desse ramo juridico: o Direito originário, o Direito derivado, o Direito complementar e o Direito jurisprudencial, ressaltando, com relação a este último, a criação de um mecanismo inovador: o reenvio prejudicial.

Juiz de Diteito do Princiro Tribunal de Algada Civil de Sa Paulo. Conselheiro da Escuela de Derecho Comunitario del Mercosur (Montevidei, Unuguai). Membro do JURSSUL - Instituto Thteramericano de Estudos Jurdicos sobre o Mercosul. 
ABSTRACT: Because of the tendency all over the planet on grouping macroeconomic regional blocks, the study of the Community Law, as a new law's subject, has becoming a necessity not only among the responsible by the project destination, but also among those that have already understood that globalization, more than irreversible, is "irresistible". It makes some considerations on the Community Law, providing introductory directions, conception, definition, principles and sources. It emphasizes the modalities of the origin of this juridical subject: the original Law, the derivative Law, emphasizing, regarding the last one, the creation of a new mechanism - the prejudicial re-sending.

RESUMEN: Discute que, en la vista de la tendencia, todo sobre el planeta, de la formación de bloques regionales macroeconómicos, el conocimiento del derecho comunitario, rama de una nueva ley, tenga necesidad que se convierte no solamente entre el responsable al lado de la destinación del proyecto, pero también entre los que han entendido ya que la globalización, tmás que irreversible, es "irrestible". Hace algunas consideraciones en el derecho comunitario, proporcionando direcciones, el concepto, la definición, principios y fuentes introductorias. Acentúa las modalidades de las fuentes de este ramo jurídico: lo derecho original, lo derecho derivado, acentuando, con respecto el pasado, la creación de un nuevo mecanismo-re-envio prejudicial.

PALAVRAS-CHAVES: Direito COMunitário. MERCOSUL. Globalização.

KEY-WORDS: European Community law. MERCOSUR. Globalization.

PALABRAS LLAVES: Ley de la Comunidad Europea. MERCOSUL. Globalización. 


\section{Introdução}

Não é de hoje que, mediante acordos, convênios e tratados, os países buscam cooperação mútua em diversas áreas da atividade humana. Há muito que a cooperação científica ganhou destaque no aprimoramento da Medicina e da Engenharia. Modernamente a Ecologia tem encontrado campo fértil entre os pesquisadores de todo o mundo, do que decorreram e vêm decorrendo vários protocolos e diplomas multinacionais. Cuida-se das conseqüências do que se convencionou chamar "mundialização" ou "globalização", fenômeno irresistivel e avassalador, que mereceu de Ricardo Lewandowski, Desembargador do Tribunal de Justiça de São Paulo e Professor na Faculdade de Direito da Universidade de São Paulo, as seguintes considerações:

O fenómeno da globalização, que alguns consideram a terceira Revolução Industrial (a primeira, consistente na aplicação da máquina a vapor aos processos industriais e a segunda, correspondente à automação dos processos produtivos), resulta de um novo modo de produção capitalista, organizado em escala planetária (Mac Donald's, Internet, desnacionalização dos processos industriais, CNN).

A globalização, entretanto, vem sendo fator determinante na cooperação, que busca entre as naçóes um fortalecimento regional no domínio da economia.

Acordos, convênios e tratados vêm sendo freqüentemente firmados nesta década de 90, ora introduzindo zonas de livre comércio, ora instalando verdadeiros blocos regionais macroeconômicos.

O Direito não poderia deixar de posicionar-se diante dessa realidade. Sempre que se fala em associaçôes, ou sempre que se cuida de regrar relacionamentos - comerciais, como na espécie - desponta o interesse humano de estabelecer conceitos e definições. Ibi societas, ubi jus.

Assim, quando se trata de unióes aduanciras ou de zonas de livre comércio, fala-se costumeiramente em Direito Internacional Público ou Privado. Mas, quando se tem em mente um espaço de soberania comum, fortalecido pela competitividade do conjunto em contraposição aos desafios internacionais, ingressa no conhecimento jurídico um Direito novo, comum aos países cooperados e, bem por isso, denominado Direito Comunitário. 
Em se tratando, pois, de um Direito comum, aplicável ao relacionamento decorrente de uma "cooperativa de países", por assim dizer, não há de se falar em Direito Internacional, mas em Direito interno, exercitado pelos nacionais, mas de forma supranacional, isto é, acima dos interesses puramente nacionais.

Não é isso o que acontece no Nafta (North American Free Trade Association), unindo Canadá, Estados Unidos e México por meio de interesses comerciais esparsos.

E nem é o que acontece no Mercosul, embora não pretendamos ser apenas uma zona de livre comércio, mas um verdadeiro mercado, tais as instituições com que já contamos: Conselho do Mercado Comum, Grupo Mercado Comum, Comissão de Comércio, Comissão Parlamentar Conjunta, Foro Consultivo Econômico-Social e Secretaria Administrativa ${ }^{2}$.

Escrevendo sobre a questão, assinalaram Jaime César Lipovetzky e Daniel Andrés Lipovetzky, advogados e professores da Universidade de La Plata:

A polêmica instalou-se mesmo antes da assinatura do Tratado de Assunção, em março de 1991. Para Alieto Guadagni, ex-Secretário de Relações Econômicas Internacionais do Ministério de Relaçóes Exteriores e Cultuta da Argentina, e como tal, protagonista destacado daquele sucesso, não cabem dúvidas: "o Mercosul não pretende ser uma zona de livre comércio entre os quatro países, mas ambiciona criar um verdadeiro espaço económico comum que fortaleça as vantagens competitivas do conjunto para lograr uma inserção mais adequada nos mercados internacionais" ${ }^{3}$.

Contudo - prosseguem os juristas, são bastante correntes as opiniões dos que - em troca - sustentam que o "Tratado de Assunção estabeleceu, fundamentalmente, um compromisso entre os quatro países para a formação de uma zona de livre comércio". Simonsen e Associados - por exemplo -, consultores e assessores de empresas multinacionais (é deles a citação), com subsidiárias em muitos países e, pelo menos, também em três dos quatro integrantes do Mercosul, em um trabalho sobre o tema subtitulado $O$ Desafio do Marketing da Integração, explicam que "as linhas básicas para a criação de um mercado comum foram abordadas apenas como objetivo dos países, de forma genérica e superficial" ${ }^{4}$. 
Assim sendo, ainda que na Carta de Ouro Preto se tenha cogitado da criação, no Mercosul, de um Tribunal transnacional ${ }^{5}$, a exemplo do que aconteceu na Europa com o Tratado de Romá, não se pode falar em Direito Comunitário na América do Sul ou na América do Norte. Ao contrário, entretanto, o conhecimento desse ramo do Direito tem quase meio século de experimentação na Europa, com o bem sedimentado Mercado Comum Europeu, hoje constituído pelos seguintes diplomas:

(...) os tratados de Paris e de Roma, alterados desde 1958 pelos tratados de Bruxelas, de 8 de abril de 1965, de fusão dos executivos; de Luxemburgo de 22 de abril de 1970; de Bruxelas, de 22 de julho de 1975, em matéria orçamental; e pelo de 10 de julho de 1975, que altera os estatutos do Banco Europeu de Investimento; o Tratado de 13 de março de 1984, que altera os tratados que instituem as Comunidades Européias no que diz respeito à Groelândia; o Ato Único Europeu, assinado em Luxemburgo e em Haia, em 17 e 28 de fevereiro de 1986; e o Tratado da União Européia, assinado em Maastricht, em 7 de feverciro de 1992; o Tratado rclativo à adesão e o ato relativo às condiçôes de adesão de três novos Estados-membros, de 22 de janeiro de 1972; o Tratado relativo à adesão e o ato relativo às condiçōes de adesão da República Helênica e às adaptaçóes dos tratados, de 24 de maio de 1979; o Tratado relativo à adesão e o ato relativo às condiçóes de adesão do Reino de Espanha e da República Portuguesa e às adaptacóes dos tratados, de 12 de junho de $1985(. .)^{7}$; o Tratado relativo à adesão e o ato relativo às condições de adesão da Finlândia, Suécia e Áustria.

Realmente, ao contrário de uma zona de livre comércio, o mercado comum se caracteriza pelo estabelecimento de cinco liberdades, todas elas devidamente asseguradas no sistema europeu pelo Direito Comunitário: a livre circulação de mercadorias, a liberdade de estabelecimento, a livre circulação de trabalhadores, a livre circulação de capitais e a liberdade de concorrência ${ }^{8}$.

Dessa forma, nada existindo entre nós senão um mero compromisso para a formação de um mercado comum, o certo é que, no estágio atual do relacionamento que mantemos com os demais países do Mercosul, podemos falar de Direito Comunitário tão-só com base na expectativa de aproveitamento da experiência européia, que poderá ser largamente utilizada no hemisfério sul, se realmente atingirmos os objetivos do Tratado de Assunção.

\footnotetext{
LOBO, 1997. p. 114

COMUNIDADES, 1984. L-2985. p.3.

LOUIS, 1993. p. 91.

BAPTISTA; MERCADANTE E CASELLA, 1994. p.12.
} 


\section{O Direito Comunitário: Definições e Fontes}

Novo ramo das ciências jurídicas aplicado à Economia, o Direito Comunitário é o conjunto de regras adotado por comunidades integradas, para regular as relações multilaterais entre os Estados-membros, particulares e instituições criadas pelo sistema.

Esse Direito novo, tertium genus que se situa entre o Direito interno e o Direito Internacional, aplicado a sistemas integrados de política econômica, tem origem remota em tratados comerciais, mas se desenvolveu extraordinariamente a partir do período "pós-guerra fria", em especial com a celebração do Tratado de Maastricht, da Comunidade Econômica Européia, hoje regulando as relações comerciais de nada menos que quinze países (Alemanha, Áustria, Bélgica, Dinamarca, Espanha, França, Grécia, Holanda, Inglaterra, Irlanda, Itália, Finlândia, Luxemburgo, Suécia e Portugal).

Enquanto disciplina jurídica nova - escreveu o já citado Professor Lewandowski -, possui também um método próprio, empregando instrumentos gnoseológicos e hermenêuticos especiais, sem prescindir daqueles do Direito interno e Internacional.

Diante das dificuldades na interpretação das normas do Direito Comunitário, traduzidas para os idiomas dos países que integram a comunidade européia, emprega-se a interpretação teleológica ou finalística, que leva em consideração os objetivos do Tratado, expressos em princípios, quais sejam: 1) da igualdade (que proíbe qualquer discriminação implícita ou explícita entre os membros ou as pessoas); 2) da liberdade (de circulação de pessoas, de mercadorias, capitais e de prestação de serviços); 3) da solidariedade (entre os Estados-membros); e, por fim, 4) da unidade (jurídica e econômica).

Mas, certamente, os princípios mais importantes são: 1) o princípio da autonomia da ordem jurídica comunitária; 2) o princípio da cooperação entre o Direito Comunitário e o interno; 3) o princípio da aplicabilidade direta do Direito Comunitário; e 4) o princípio da supremacia do Direito Comunitário sobre o Direito interno que lhe é contrário?.

A principal fonte do Direito Comunitário, portanto, reside nos tratados internacionais. Assim, quando convertidos em leis nos países signatários, esses tratados não são senão fontes imediatas de Direito, na divisão clássica da doutrina de Washington de Barros Monteiro.

"LEWANDOWSKI, 199. 
Inspirado em Planiol (Traité Élémentaire de Droit Civil), o renomado civilista brasileiro ensina que fontes diretas ou imediatas são aquelas que, por si sós, pela sua própria força, são suficientes para gerar a regra jurídica. São a lei e o costume ${ }^{10}$.

As indiretas ou mediatas, por outro lado, são as que não têm tal virtude, porém encaminham os espíritos, mais cedo ou mais tarde, à elaboração da norma ${ }^{11}$.

No Direito Comunitário, dessa forma, as fontes imediatas são as que, constituídas pelos tratados, foram classificadas por Jean Boulouis de conjunto formado pelo "Direito originário", em obediência à cronologia e à técnica de estudo ${ }^{12}$.

Do Direito originário surgem as fontes do Direito derivado, segundo conjunto de regras, repousando nos atos unilaterais das instituições comunitárias.

O terceiro conjunto de regras desponta nos atos convencionais, concluídos entre os Estados-membros ou por estes com a Comunidade e com Estados não participantes do sistema. O hábito europeu os designou como fontes do Direito complementar.

A essas fontes, finalmente, veio juntar-se uma quarta categoria: o Direito jurisprudencial, constituído pelos arestos das Cortes Supranacionais. Ce droit revêt une importance particulière en raison des fonctions attribuées à la Court par les traités et de la manière dont celle-ci les conçoit ${ }^{13}$.

Daí o quadro sinótico das fontes em Direito Comunitário, assim representado: diretas ou de Direito originário; de Direito derivado; e indiretas: de Direito complementar e de Direito jurisprudencial.

\section{O Direito Originário}

O Direito originário, como já assentado, é fonte que se acha nos instrumentos internacionais, formadores iniciais e em continuação do ordenamento jurídico de uma comunidade econômica.

Na Europa, dentre outros, destacam-se o Tratado do Ceca ( $L a$ Communauté Européenne du Charbon et de l'Acier), o Tratado de Roma (Europa dos Seis), o Tratado de Maastricht etc. Na América do Sul, contase especialmente com o Tratado de Assunção e os protocolos posteriores (de Brasília, de Ouro Preto etc.).

\footnotetext{
${ }^{10}$ MONTEIRO, 1989. p. 12.

${ }^{11}$ Idem.

2 BOULOUIS, 1995. p. 194.

13 Ibidem. p. 195.
} 
Os tratados genuinamente comunitários são dotados de duas proposições fundamentais: de um lado, distinguem-se claramente de outros por buscar a criação de um mercado comum; essa distinção se acentua quando, de outro lado, procuram os referidos instrumentos a instituição de organismos internacionais destinados a gerenciar a sedimentação e a evolução desse mercado.

Sob o aspecto da primeira proposição, os tratados comunitários se distinguem segundo instituam os mercados ditos setoriais - na Europa, o Ceca; na América do Sul, entre outros, a União Aduaneira BrasilArgentina, a Associação Latino-Americana de Livre Comércio (Alalc), a Associação Latino-Americana de Integração (Aladi), o Programa de Integração e Cooperação Econômica entre a Argentina e o Brasil (Picab), o Tratado de Integração Brasil-Argentina -, ou segundo instituam um mercado comum de amplitude geral - na Europa, o Tratado de Maastricht; na América do Sul, o Tratado de Assunção, com as restrições já sublinhadas anteriormente.

Na América do Norte, o Nafta, ou North American Free Trade Association, não pode ser considerado como um tratado que busque instituir um mercado comum. Conforme acentuam Jaime e Daniel Lipovetzky, apesar das diferenças institucionais e juridicas entre os conceitos de zona de livre comércio e mercado comum, que, ainda que apenas esboçados, se expressam tão nitidamente, há autores que persistem em confundi-las.

Carlos Tavares de Oliveira, por exemplo, em um trabalho sobre Comércio Exterior e a Questão Portuária, afirma com nenhum fundamento que "agora o Mercado Comum Norte-Americano (incluindo o Canadá) é uma auspiciosa realidade"(?). À margem do erro conceitual, que não podemos desculpar em um trabalho prefaciado nada menos que pelo ex-Ministro brasileiro de Economia, Fazenda e Planejamento, no ano de 1992, Sr. Marcílio Marques Moreira, faz-se necessário investigar os "porquês" de tão peregrina afirmação. É que o autor, ex-titular da Carteira de Comércio Exterior do Brasil, foi também, a partir de 1965, assessor da Confederação Nacional de Comércio, o que nos autoriza a supor que suas idéias e interpretações podem estar influindo em uma boa parte dos setores políticos e empresariais que estiveram vinculados ao governo do Presidente Collor de Mello. Talvez, tanta confusão conceitual esteja induzida de ex profeso pela ambigüidade das expressões 
incluídas no texto daquele outro acordo sobre comércio e inversão, firmado pelos quatro países integrantes do Mercosul e os Estados Unidos da América (Quatro Mais Um), relativo a um conselho sobre comércio e inversão (19 de junho de 1991).

É que, em suas cláusulas, o trabalho de conformar as partes chega até o extremo de aparentar indiferenças sobre a "iniciativa para as Américas do Presidente Bush, particularmente no estímulo às políticas governamentais de mercado" (considerando 3) e o espírito do Tratado de Assunção ${ }^{14}$.

Os tratados setoriais contêm uma regulamentação econômica suficientemente desenvolvida. Bem por isso, săo comparados às leis self executing.

Os tratados gerais, a seu turno, surgem na forma de textos conceituais, definindo objetivos e introduzindo princípios e regras que buscam assegurar a consolidação e o desenvolvimento do sistema, pela edição do Direito derivado.

$\mathrm{Na}$ edificação do Direito Comunitário europeu, portanto, estabeleceu-se um nítido divisor de águas sobre a natureza das regras, conforme venham a ser encontradas nos tratados ou no Direito derivado. Assim é que, sob a ótica de cada um dos Estados-membros, ficou claro, com a sedimentação do regime, que, nas relações do Direito nacional com o Direito supranacional, as disposições dos tratados e as do Direito derivado passaram a ocupar cada qual um espaço próprio, técnica e cronologicamente diverso um do outro.

\section{O Direito Derivado}

Embora na América do Sul possamos elencar diversos tratados como fontes de Direito originário, sob o aspecto do Direito derivado, a experiência européia é que nos traz maiores subsídios.

Segundo Jean Boulois ${ }^{15}$, sob o nome de Direito derivado se designam costumeiramente as fontes formais oriundas dos atos unilaterais das instituições comunitárias criadas pelos tratados.

Nos termos dos tratados europeus, portanto, os atos dessas instituiçōes surgiram na forma de cinco categorias: os regulamentos, as diretivas, as decisões, as recomendações e os pareceres. Fala-se, ainda, em deliberações e programas gerais.

Os regulamentos são atos de caráter geral e obrigam toda a comunidade, seja as pessoas jurídicas de Direito público, seja as de Direito

17 LIPOVETZKY E LIPOVETZKY, 1994. p. 57-58.

15 BOULOIS, 1995. p. 202. 
privado ou os particulares. As diretivas ora obrigam de forma geral os Estados-membros e as pessoas jurídicas de Direito privado, ora obrigam apenas os primeiros. As decisões são atos administrativos que obrigam tão-só os destinatários. As recomendações e os pareceres, finalmente, são atos meramente programáticos e, uma vez não obrigando, escapam ao controle jurisdicional.

\section{O Direito Complementar}

Um terceiro conjunto é constituído por atos convencionais ligados à existência das Comunidades Européias, havendo o repertório oficial da legislação comunitária em vigor lhes emprestado a qualificação de Direito complementar.

Essa categoria de fonte funda-se sobretudo nas decisões das representações governamentais de cada um dos Estados-membros, quando reunidos em conselho, embora lato sensu possam ter dupla origem: de um lado, na natureza convencional já mencionada e, de outro, nas leis nacionais de conteúdo supranacional.

\section{O Direito Jurisprudencial}

Conta-se, finalmente, com a jurisprudência como fonte de Direito Comunitário. Na Europa, ela é constituída pelos julgados dos tribunais de Luxemburgo de primeira e segunda instâncias. Tendo em vista a competência atribuída ao Judiciário europeu pelo Tratado da União, cuidase de uma fonte essencialmente comunitária.

A exceção das decisões erga omnes, advindas das ações de anulação, as demais do Judiciário europeu não têm outra autoridade senão a da coisa julgada entre os interessados.

Como no Direito comum, não raramente o Judiciário europeu lança mão dos princípios gerais de Direito, bem assim dos direitos fundamentais, na construção da jurisprudência comunitária.

No que diz respeito aos princípios, a jurisprudência comunitária fundou o respeito pela segurança jurídica na Comunidade, exemplificativamente por meio do princípio da não-retroatividade dos atos administrativos baixados pelas instituiçôes comunitárias (CICE 29/ 1/85, Gesamthochschule Duisburg, 234/83), do princípio do direito 
adquirido mesmo na diversidade das culturas e da imutabilidade das situações jurídicas subjetivas (CJCE 22/9/83, Verli Wallace, 159/82), do prinć́pio da boa-fé imposta às instituições, tanto na área administrativa como na contratual (CJCE 15/7/60, Van Lackmüller, 43/59) etc.

A questão dos direitos fundamentais foi colocada perante a Corte de Justiça das Comunidades Européias em 1960 (CJCE 15/7/60, Cptoirs de Vente de charbons de la Ruhr, 36/59), a propósito de uma contradição que os trabalhadores acreditavam existir entre as obrigaçôes que lhes impunham certas decisões das altas autoridades do Tratado do Carvão e do Aço. A partir de então - e até a atualidade - a jurisprudência européia vem-se preocupando com os direitos humanos em seus arestos: o direito de propriedade e o direito do livre exercício das atividades profissionais (CICE 14/5/74, Nold, 4/74, 13/12/79, Hauer 44/79, 18/3/80, Valsabbia, 154/78, 19/7/85, Hoogovens Groep, 17/2/83, 8/10/86, Keller); o princípio da não-retroatividade das disposições penais (CJCE 10/7/84, Kent Kirk, 63/83); o princípio da não-discriminação em razão do sexo (CJCE 15/6/78, Defrenne, 149/77); o direito de respeito à intimidade e o direito da proteção ao segredo médico (CICE 8/4/92, Commission c. R.F.A, C-62/90).

Essa copiosa fonte de um Direito novo - a jurisprudência européia - teve, dentre os mecanismos normais de produção, um outro mecanismo, de ordem especialíssima e até inovador para a sedimentação do sistema - denominado "reenvio prejudicial" ou "recurso prejudicial" -, espécie de diálogo escrito entre os juízes nacionais e os supranacionais, que assegurou a aplicação uniforme do Direito Comunitário em todos os países-membros da comunidade.

Antigo juiz da Corte Suprema de Luxemburgo, Pierre Pescatore, hoje aposentado, escreveu sobre o instituto: se é verdade que o recurso prejudicial conheceu um extraordinário sucesso no que se refere as Comunidades Européias, é certo, no entanto, que ele não é uma inovação dos autores dos tratados europeus. Mecanismos judiciários semelhantes são conhecidos no Direito interno de vários Estados-membros, como, por exemplo, nas relaçôes entre jurisdiçôes civis, penais e administrativas.

$O$ recurso prejudicial ocupa mesmo um lugar particularmente importante na organização dos tribunais constitucionais. Assim, ele é utilizado correntemente na jurisdição constitucional da Alemanha e da Itália, onde os juízes têm possibilidade ou mesmo a obrigação de apresentar, perante o Tribunal Constitucional, problemas de constitucionalidade surgidos nos processos sob sua jurisdição; a Espanha adotou o mesmo sistema no tocante à sua nova Constituição ${ }^{16}$.

16 PESCATORE, 1986. p. 7. 


\section{Conclusão}

O modelo europeu, no qual se destaca especialmente a jurisdição européia, revelou-se apropriado à necessidade da integração, buscando o fortalecimento de um determinado bloco macroeconômico regional, tal como o que se vem formando entre nós.

Não se desconhece haver, mesmo na Europa, vozes dissonantes que se erguem veementemente contra essa nova ordem universal, a nosso ver irresistivel.

Citado pela Professora Deisy de Freitas Lima Ventura, assim se manifestou o jurista francês François Furet: esse mercado curopeu ocidental, a uma só vez ampliado e protegido, tende a produzir uma proliferação de regulamentos e leis sem que se perceba com clareza qual é o fundamento dessas normas européias.

Parece-me que, pela primeira vez na história do Ocidente, nos achamos diante de leis que não possuem um claro fundamento em algum tipo de soberania. Há muitos séculos, todos os nossos países se construíram sob a idéia de que a lei tinha seu fundamento na soberania da nação (nas mãos do rei ou, depois, na representação popular). Essa situação incerta da produça de normas européias se deve provavelmente à maneira pela qual se construiu a Europa, já há quase quarenta anos. E se as coisas não mudarem, não estará isenta de perigos no futuro. Temo, por exemplo, o desencadeamento de reações anti-européias que se alimentariam precisamente dessa distância entre a lei e a soberania ${ }^{17}$.

Ainda da mesma especialista, a virulenta crítica de outro dissidente: no mesmo debate, Bronislaw Geremek aponta uma perigosa utopia como idéa de fundo do sistema jurídico comunitário: a do Estado-Europa, que ocuparia o lugar do Estado nacional, visão muito presente sobretudo na euroburocracia. Nesse Estado imaginário (que a ultradireita francesa considera um dinossauro de 400 milhóes de habitantes), a única fonte possivel de legitimidade democrática não existe nem pode ser criada: o populus europeu ${ }^{18}$.

Ricardo Lewandowski tem outro enfoque sobre o fenômeno: atualmente, como anota Liszt Vieira na obra Cidadania e Globalização, o paradigma clássico das Ciências Sociais, baseado nas sociedades nacionais, está sendo substituído por outro - o da sociedade global -, levando à reformulação dos conceitos clássicos de soberania e de hegemonia, ainda firmemente arraigados na doutrina política e jurídica ${ }^{19}$.

\footnotetext{
17 FURET itr. DAHRENDORF; FURET e GEREMEK, 1993. p. 86. apud VENTURA, 1996. p. 115-116.

I* VENTURA, 1996. p. 116.

16. LEWANDOWSKI, $18 / 08 / 97$. p. 4.
} 
François Furet e Bronislaw Geremek certamente não levaram em consideração que o capital é abstrato e ultrapassa fronteiras sem sair do lugar. Desconhecem a realidade laboral na América do Sul, onde, pela Ponte da Amizade, circulam os fenícios tupiniquins, sacoleiros que hablam un atrevido "portunhol" e que, entre si, já estabeleceram a livre circulação de mercadorias, a liberdade de estabelecimento, a livre circulação de trabalhadores, a livre circulação de capitais e a liberdade de concorrência.

Essa ordem jurídica informal, se desprezada como um elefante que não conseguimos enxergar em nossa própria cozinha, acabará se avolumando de tal forma que dificilmente caberá no instrumento de jurisdição no qual, inexoravelmente, teremos de acomodar a polêmica para dirimir ódios e conflitos antigos, ora no nascedouro e, em conseqüência, de solução mais simples, sem traumas e sem seqüelas, se desde já adotarmos um modelo de crescimento ordenado, em consonância com a realidade.

A irmanação dos homens, não é de hoje, é idéia absorvida por poucos. Mesmo na Europa, como se viu, onde a experiencia iniciou-se há quase meio século, raros são os que assimilaram a grandiosidade do empreendimento, que repousa na renúncia de poucos direitos políticos.

No discurso do Professor Vassili Christianos, Référendaire do Tribunal de Justiça das Comunidades Européias, foi assim com a edificação da Catedral de Reims: a maioria dos obreiros entendia que talhava pedras; poucos sabiam que se erguia uma catedral ${ }^{20}$.

\section{BIBLIOGRAFIA}

BAPTISTA, Luiz Olavo; MERCADANTE, Araminta de Azevedo e CASELLA, Paulo Borba (org.). Mercosul - das Negociações à Implantaço. São Paulo:Ltr, 1994. $352 \mathrm{p}$.

BOULOUIS, Jean. Droit Institutionnel de L'union Européenne. Paris:Montchrestien, $1995.392 \mathrm{p}$.

CARTILHA do Mercosul. 2 ed. atualizada. Brasilia:Comissão Parlamentar Conjunta do Mercosul, 1996.20 p.

CHRISTIANOS, Vassili. Revista dos Tribunais. n. 717, 19-. p. 57. COMUNIDADES Européias. Corte de Justiça. O Tribunal de Justiça das Comunidades Européias. Luxemburgo:Comunidades Europétas, 1984. 60 p. FURET, François. La crisis de la Comunidade Europea y la necesidad de

CHRISTIANOS, $19-$. p. 57. 
una nueva Europa. In: DAHRENDORF, Ralf; FURET, François; GEREMEK, Bronislaw. La democracia en Europa. Madrid:Alianza, 1993. LEWANDOWSKI, Ricardo. O Juiz e o Processo de Globalização. Brasilia, Correio Braziliense, 18/08/97. p. 4.

- - trabalho inédito, 199 .

LIPOVETZKY, Jaime César e LIPOVETZKY, Daniel Andrés. Mercosul: estratégias para a integração: mercado comum ou zona de livre comércio? Análises e perspectivas do Tratado de Assunção. São Paulo:Ltr, 1994.549 p. LOBO, Maria Teresa Cárcomo. Ordenamento Jurídico Comunitário. Belo Horizonte:Del Rey, 1997.

LOUIS, Jean-Victor. A Ordem Jurídica Comunitária. Luxemburgo:Comunida-des Européias, 1993.

MONTEIRO, Washington de Barros. Curso de Direito Civil. Parte Geral, São Paulo:Saraiva, 1989.

PESCATORE, Pierre. O Recurso Prejudicial do Art. 177 do Tratado CEE e a Cooperação com as Jurisdições Nacionais. Luxemburgo:Comunidades Européias, 1986.

VENTURA, Deise de Freitas Lima. A Ordem Juridica do Mercosul. Porto Alegre: Livraria do Advogado, 1996. (Integração Latino-Americana). http://www.cif.gov.br/revista/numero6/artigo15.htm, 23/03/2001. 